\section{Cureus}

Received 03/21/2019

Review began 03/25/2019

Review ended 04/04/2019

Published 04/11/2019

\section{(c) Copyright 2019}

Maclnnes et al. This is an open access article distributed under the terms of the Creative Commons Attribution License CC-BY 3.0., which permits unrestricted use, distribution, and reproduction in any medium, provided the original author and source are credited.

\title{
Bloody Nipple Discharge in a Man with Benign Papillomas: A Case Report
}

\author{
Emma G. MacInnes ${ }^{1}$, Isobel Haigh ${ }^{2}$, Anju Nijhawan ${ }^{3}$, Brian Hogan ${ }^{1}$ \\ 1. Breast Surgery, Leeds Teaching Hospitals Trust, Leeds, GBR 2. Breast Radiology, Leeds Teaching \\ Hospitals Trust, Leeds, GBR 3. Pathology, Leeds Teaching Hospitals Trust, Leeds, GBR
}

$\square$ Corresponding author: Emma G. MacInnes, emma.macinnes1@nhs.net Disclosures can be found in Additional Information at the end of the article

\section{Abstract}

Blood-stained nipple discharge in a man would usually be proved to be male breast cancer. We present a case where this unusual presentation was associated with benign intraductal papillomas, managed with simple duct excision, preserving the patient's nipple whilst adequately investigating and managing the condition.

Categories: Pathology, Radiology, General Surgery

Keywords: nipple, discharge, papilloma, benign

\section{Introduction}

Blood-stained or other abnormal nipple discharge is associated with malignancy in $3 \%$ of women [1], with a higher rate anticipated in men presenting with this symptom. If it is associated with a palpable mass or abnormal breast imaging the rate of underlying malignancy increases. Whilst carcinoma and in situ carcinoma are possible there are other benign explanations for abnormal discharge, including physiological discharge, duct ectasia and intraductal papillomas. Cytological assessment of discharge has been demonstrated to lack sensitivity and specificity to allow it to be used to make a diagnosis and normal imaging does not exclude malignancy [2]. Duct excision is the standard of care for women with persisting spontaneous, unilateral nipple discharge to exclude an occult malignant process [3].

Intraductal papillomas are high-risk precursor lesions, with potential to progress to atypia, in situ and invasive carcinomas, with an increased risk also present in the immediately surrounding tissue and a breast cancer risk twice that of the general population [4], even after excision [5]. If needle core biopsy demonstrates a seemingly benign intraductal papilloma, it should be noted that up to $10.7 \%$ are upgraded with atypia and malignancy subsequently identified on surgical excision specimens [6]. With the presence of atypia on core biopsy, 32\% are subsequently upgraded to malignancy by surgical excision [7]. Total duct excision, for centrally sited, retroareolar papillomas, is generally well tolerated though carries the risk of nipple necrosis, nipple inversion and the loss of nipple sensation.

\section{Case Presentation}

We present a 62-year-old male patient, who presented with a few months of left-sided, episodic, blood-stained nipple discharge, occurring spontaneously and without warning. The discharge had the appearance of 'frank blood'. He had not noticed any other changes to the breast or nipple and had no history of trauma. His previous history included a mild inflammatory arthritis for which he no longer required medication and a microprolactinoma, 


\section{Cureus}

diagnosed 13 years previously, for which he required testosterone supplementation due to hypogonadotropic hypogonadism, but no other treatment. At the time of the presentation with blood stained nipple discharge, prolactin levels were within normal ranges as were other hormone assays related to his pituitary function. Cabergoline had been discontinued four years prior to presentation. There was no family history of breast cancer, he did not smoke or take alcohol in excess.

Clinical assessment found no visible or palpable abnormality in the breast disc but demonstrated the bloody discharge. Ultrasonography demonstrated subareolar ducts but no focal mass. Mammography was normal on the right but indeterminate on the left with a 16-mm asymmetry in the 9-o-clock position within the retroareolar tissue and with associated flecks of benign appearing calcification (Figure 1). Cytology of a smear of discharge showed plentiful red blood cells and histiocytes with no epithelial cells present. As duct excision was planned, core biopsy was not performed.

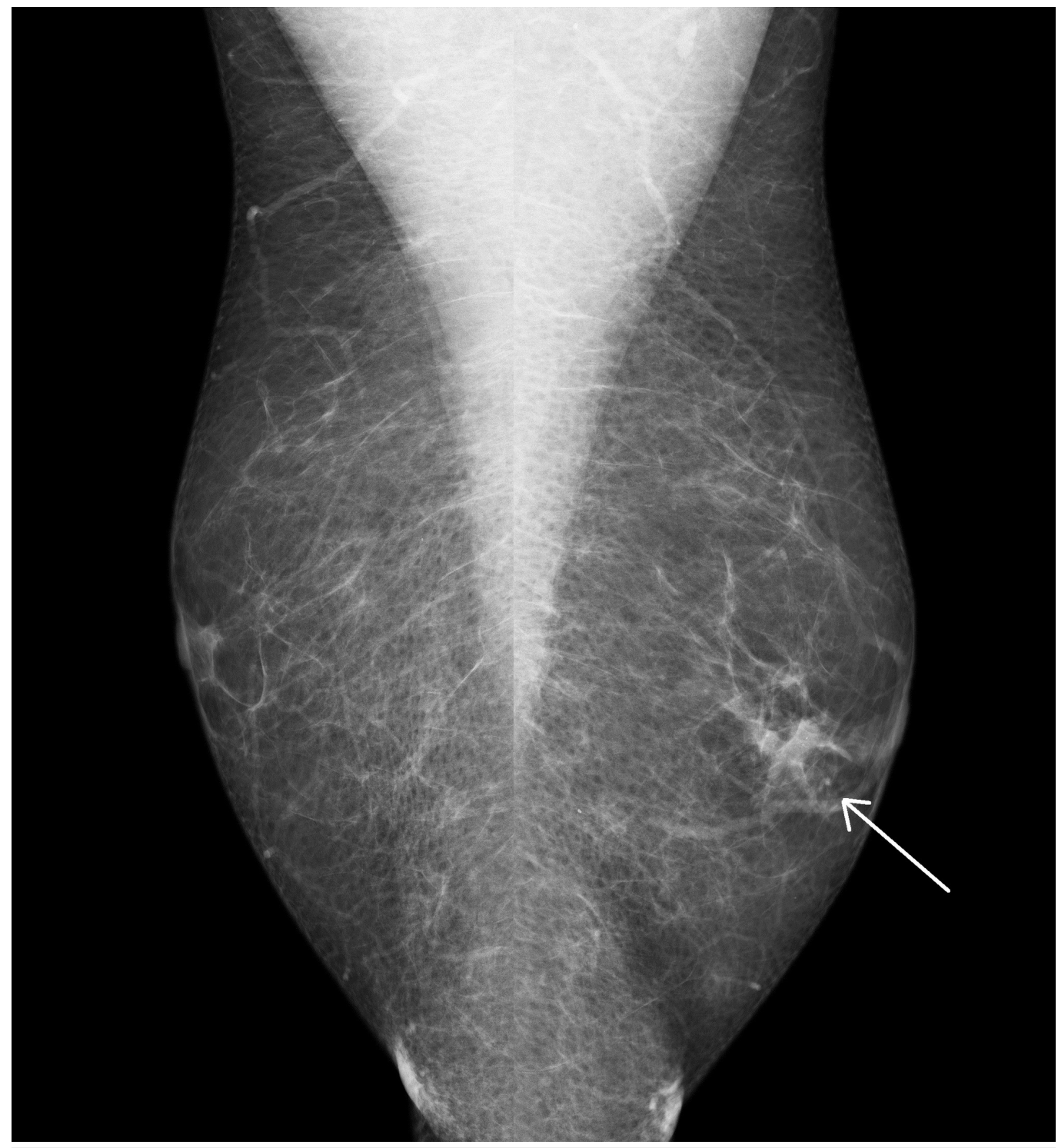

FIGURE 1: Mammography

The case was discussed in a multi-disciplinary team meeting and a left total duct excision was recommended. This was performed under general anaesthetic, with an anterior shave of tissue 
taken from behind the nipple. Pathological findings were unusual in the context of a male patient, showing a few scattered benign intraductal papillomas measuring up to $2 \mathrm{~mm}$ (Figure 2). Immunohistochemistry showed heterogenous positivity with cytokeratin (CK) 5/6. No atypia was noted. The patient made an uneventful recovery with no further reported nipple discharge and preservation of his nipple and chest wall symmetry. No surveillance is planned.

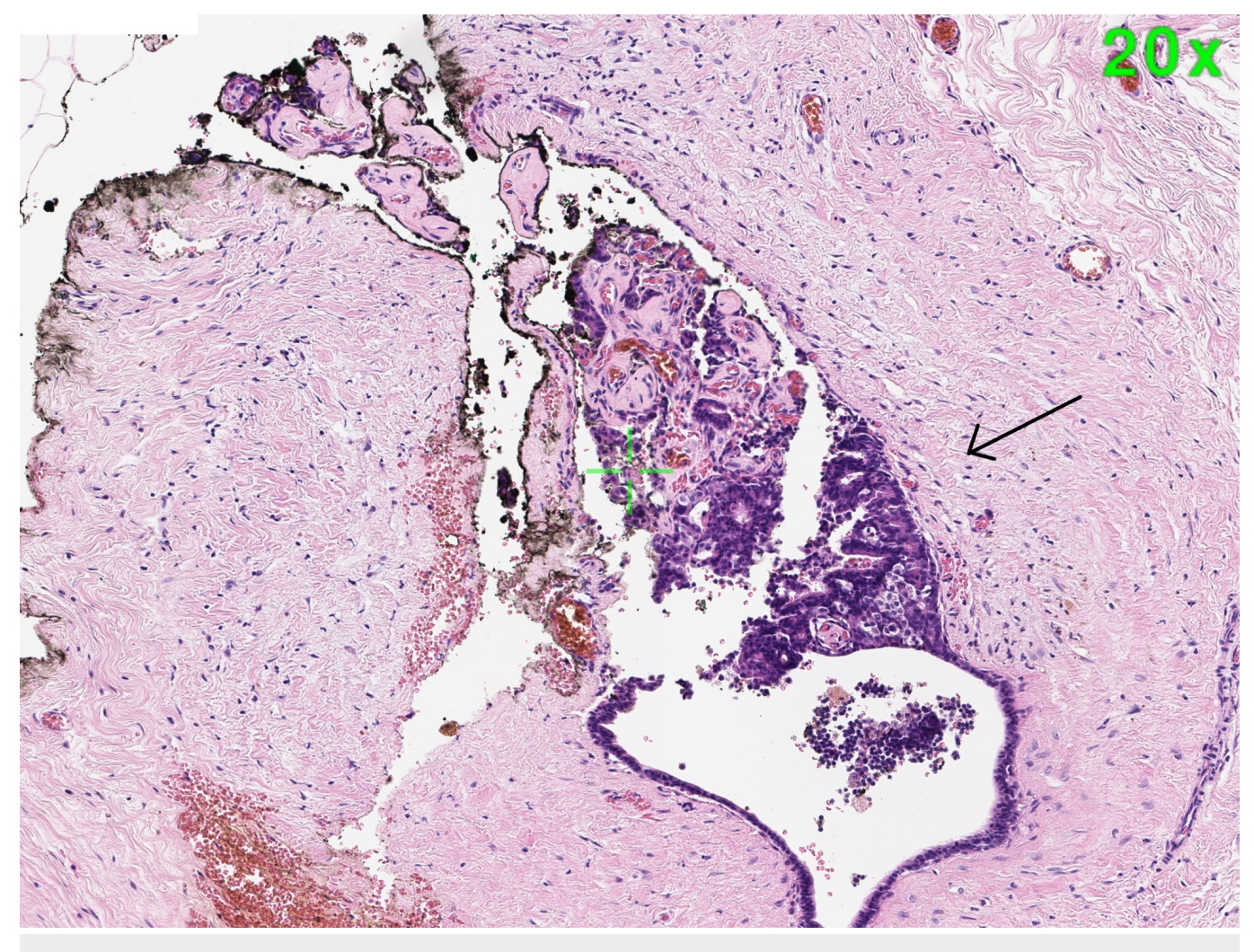

\section{FIGURE 2: Histopathology image of partially sclerosed intraductal papilloma}

\section{Discussion}

Benign intraductal papillomas in men are rare but may be the cause of blood-stained nipple discharge. Management is not gender dependent and involves clinical, radiological and pathological assessment, often requiring open surgical excision of the retroareolar tissue. The role of cytological assessment of the discharge in men is unclear and it should not be used to avoid more invasive forms of biopsy. If cytology demonstrates malignancy, however, treatment could proceed directly to mastectomy potentially avoiding the need for two operations. The tendency to assume that nipple symptoms in men are due to malignancy could equally have resulted in disfiguring overtreatment. The risk of future malignancy in men with breast papillomatosis is not known. Whether there is a role for surveillance, particularly in cases with atypia, is unclear but this could be considered.

\section{Conclusions}

Men presenting with bloody nipple discharge must be assumed to have breast malignancy until proven otherwise. This case does, however, illustrate the fact that anything from the spectrum of benign breast disorders seen in women can also be seen, albeit rarely, in men. Performing a mastectomy would have been significant overtreatment of a benign pathology. Duct excision can be safely performed in men and provides an opportunity to preserve the aesthetics of the 
male breast whilst investigating the cause of and treating suspicious nipple discharge.

\section{Additional Information \\ Disclosures}

Human subjects: Consent was obtained by all participants in this study. Conflicts of interest: In compliance with the ICMJE uniform disclosure form, all authors declare the following:

Payment/services info: All authors have declared that no financial support was received from any organization for the submitted work. Financial relationships: All authors have declared that they have no financial relationships at present or within the previous three years with any organizations that might have an interest in the submitted work. Other relationships: All authors have declared that there are no other relationships or activities that could appear to have influenced the submitted work.

\section{References}

1. Gray RJ, Pockaj BA, Karstaedt PJ: Navigating murky waters: a modern treatment algorithm for nipple discharge. Am J Surg. 2007, 194:850-855. 10.1016/j.amjsurg.2007.08.027

2. Simmons R, Adamovich T, Brennan M, Christos P, Schultz M, Eisen C, Osborne M: Nonsurgical evaluation of pathologic nipple discharge . Ann Surg Oncol. 2003, 10:113-116. 10.1245/ASO.2003.03.089

3. Cancer diagnosis. (2010). Accessed: November 18, 2018: https://associationofbreastsurgery.org.uk/media/64328/cancer-diagnosis-v1.pdf.

4. Swapp RE, Glazebrook KN, Jones KN, Brandts HM, Reynolds C, Visscher DW, Hieken TJ: Management of benign intraductal solitary papilloma diagnosed on core needle biopsy . Ann Surg Oncol. 2013, 20:1900-1905. 10.1245/s10434-012-2846-9

5. Khan S, Diaz A, Archer KJ, Lehman RR, Mullins T, Cardenosa G, Bear HD: Papillary lesions of the breast: to excise or observe?. Breast J. 2018, 24:350-355. 10.1111/tbj.12907

6. Tran HT, Mursleen A, Mirpour S, Ghanem O, Farha MJ: Papillary breast lesions: association with malignancy and upgrade rates on surgical excision. Am Surg. 2017, 83:1294-1297.

7. Forester ND, Lowes S, Mitchell E, Twiddy M: High risk (B3) breast lesions: what is the incidence of malignancy for individual lesion subtypes? A systematic review and metaanalysis. Eur J Surg Oncol. 2019, 45:519-527. 10.1016/j.ejso.2018.12.008 